\title{
MODIFICATION OF THE EEDI FOR RO-RO PASSENGER SHIPS
}

\author{
Ivica ANČIĆ*, Ante ŠESTAN, Nikola VLADIMIR \\ University of Zagreb, Ivana Lučića 5, 10000 Zagreb, CROATIA \\ E-mail: ivica.ancic@fsb.hr, tel.+38516168257, fax.+38516156940
}

\begin{abstract}
In the 3rd IMO GHG study the new data on the ships emissions indicate a clear need for improvements in ship energy efficiency in order to preserve the environment. Although the majority of the pollution originates from the international shipping, the environmental impact of the short-sea shipping, primarily from ro-ro passenger ships, should not be neglected. The pollution originating from these ships is especially pernicious for public health since they operate in and near ports and highly populated areas. The newest amendments to MARPOL Annex VI introduce the Energy Efficiency Design Index (EEDI). The EEDI should be a measure of ships energy efficiency, but its application is limited since it may not be applied to ships with diesel-electric or hybrid propulsion systems. Also the EEDI seems not to be feasible for the regulation of energy efficiency for ro-ro passenger ships because their design criteria vary too much.
\end{abstract}

The aim of this paper is to propose a new approach to the EEDI definition for ro-ro passenger ships. It introduces the Reference surface as the function of ships capacity and speed instead of the Reference line. It also expands the attained EEDI calculation to different loads trying to give a clearer view of the ships $\mathrm{CO}_{2}$ emission. This modified EEDI would then allow a fair comparison between different ro-ro passenger ships.

KEY WORDS: EEDI, ro-ro passenger ships, energy efficiency, $\mathrm{CO}_{2}$ emission, environmental impact

\section{INTRODUCTION}

Ship transportation offers many benefits and is considered the cheapest and the most energy efficient way of transporting large quantities of cargo. Still, it was estimated that in 2012 global shipping emitted about 1,016 million tonnes of $\mathrm{CO}_{2}$ which constituted about $3.1 \%$ of the global $\mathrm{CO}_{2}$ emission (Third IMO GHG study, 2014). This emission is highly correlated with the fuel consumption, as well as other emissions to air, namely $\mathrm{NO}_{\mathrm{X}}, \mathrm{SO}_{\mathrm{X}}$ and $\mathrm{PM}_{10}$.

Marine Environment Protection Committee (MEPC) recognized this issue and at its $62^{\text {nd }}$ session adopted Resolution MEPC.203(62) (MEPC, 2011a) which includes amendments to MARPOL Annex VI. It introduces new chapter 4 which intends to improve energy efficiency for ships through a set of technical performance standards. The amendments, which entered into force on 1 January 2013, require that every ship has the International Energy Efficiency (IEE) Certificate on board. In order to obtain the IEE Certificate a ship has to comply with the Energy Efficiency Design Index (EEDI) and the Ship Energy Efficiency Management Plan (SEEMP). The EEDI is mandatory for all new ships and SEEMP for all ships of 400 GT and above engaged in the international shipping. The attained EEDI calculated for a ship must not be higher than the required EEDI, while the SEEMP must be developed for a ship according to Guidelines and kept on board (MEPC, 2011a).

EEDI and SEEMP represent a technical and an operational measure to reduce the $\mathrm{CO}_{2}$ emission from ships respectively. The introduction of this regulation was preceded by the Second
IMO GHG study (2009) which revealed a significant potential for the reduction of the GHG emission through these measures, even by $25 \%$ to $75 \%$ below the current levels. Moreover, many of these measures appear to be cost-effective, although nonfinancial barriers may discourage their implementation (MEPC 2011b). MEPC is considering also market based measures (MBM), but has not introduced them so far.

MEPC also adopted several guidelines to ensure smooth and uniform implementation of these regulations. These include the attained EEDI calculation guidelines (MEPC, 2014), guidelines for the calculation of the reference lines (MEPC, 2012) and others.

\section{RO-RO PASSENGER SHIPS}

"Ro-ro passenger ship" means a passenger ship with roll-on-rolloff cargo spaces (MEPC, 2011a), Figure 1. These ships in 2012 emitted about 30.1 million tonnes of $\mathrm{CO}_{2}$. If also passenger (cruise ships and ferries) and ro-ro ships are added to this number, their total $\mathrm{CO}_{2}$ emission in 2012 was about 107.4 million of tonnes. That represents roughly $10 \%$ of the total world seaborne $\mathrm{CO}_{2}$ emission. But the pollution originating from these ships is especially pernicious for public health, since they are engaged in short sea shipping and their pollution occurs mostly in and near ports. For instance, this is particularly pronounced in Dubrovnik, Croatia, where the annual deposition of sulfur in the amount of $9.16 \mathrm{~kg} / \mathrm{ha}$ is by far the highest in Croatia and is probably the result of its being a popular port of call for cruise ships (Runko Luttenberger et al, 2013). 


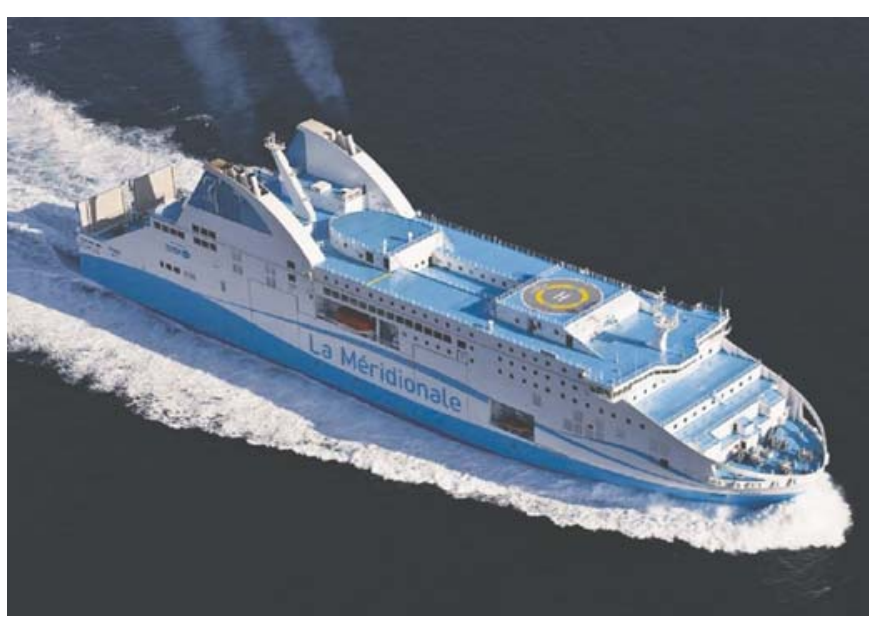

Figure 1. Ro-ro passenger ship Piana (www.brodosplit.hr)

Ro-ro passenger ships are specific since their design criteria vary significantly due to the variation in the operation demands. Another characteristic of these ships is that they need to have excellent maneuverability and enough power to maintain the course and speed in rough weather to ensure safety and reliability. In this case the ecological eligibility is not of primary importance. Also, the number of passengers and/or cars the ship can transport is dictated by transport needs. This number is rarely optimal regarding the ship energy efficiency.

Because of that, many ro-ro passenger ships have unconventional power systems, such as integrated power systems (characterized by centralized production of electrical energy) or hybrid power systems (characterized by different types of power sources)

\section{CURRENT APPROACH}

The attained EEDI calculation guidelines (MEPC, 2014) describe in detail the formula for the EEDI calculation (1). The numerator in the EEDI formula generally represents mass flow of the $\mathrm{CO}_{2}$ produced based on the ship systems power needs, and the denominator represents benefit for the society. So the EEDI is measured in $\mathrm{g} \mathrm{CO}_{2} / \mathrm{t} \mathrm{nm}$.

That value is adjusted with various correction factors: $f_{j}$ to account for ship specific design elements, $f_{i}$ a capacity correction factor, $f_{c}$ the cubic capacity correction factor, $f_{l}$ the factor for ships equipped with cargo related gear and $f_{w}$ indicating the decrease of speed in representative sea conditions. Especially important for ro-ro passenger ships are the correction factors $f_{\text {iRoRo }}, f_{i V S E}, f_{\text {RoRo }}$ and $f_{c R o P a x}$, which have been introduced in order to better represent the ship energy efficiency by the attained EEDI.

$f_{j R o R o}$ is a correction factor to account for ship specific design elements and calculated as:

$$
f_{j R o R o}=\frac{1}{F_{n_{L}}^{\alpha} \cdot\left(\frac{L_{p p}}{B_{s}}\right)^{\beta} \cdot\left(\frac{B_{s}}{d_{s}}\right)^{\gamma} \cdot\left(\frac{L_{p p}}{\nabla^{1 / 3}}\right)^{\delta}}
$$

where $F n_{L}$ is the Froude number, $L_{p p}$ is the length between perpendiculars, $B_{s}$ is the breadth, $d_{s}$ is the summer load line draught and $\nabla$ is the volumetric displacement, while the exponents are defined as:

$$
\begin{array}{ll}
\alpha=2.50 & \gamma=0.75 \\
\beta=0.75 & \delta=1.00
\end{array}
$$

For ships with voluntary structural enhancements $f_{i V S E}$ is expressed by formula:

$$
f_{i V S E}=\frac{D W T_{\text {referencedesign }}}{D W T_{\text {enhanceddesign }}}
$$

For ships with ro-ro ramps $f_{\text {RoRo }}$ should be defined as:

$f_{\text {RoRo }}=\frac{\text { Capacity }_{\text {No RoRo }}}{\text { Capacity }_{\text {RoRo }}}$

and calculated in analogy to $f_{i V S E}$. For ro-ro passenger ships having a DWT/GT ratio of less than 0.25 , the following cubic capacity correction factor, $f_{\text {cRoPax }}$, should also apply:

$f_{\text {cRoPax }}=\left(\frac{(D W T / G T)}{0.25}\right)^{-0.8}$

At the MEPC 66 session in April 2014 new amendments have been adopted in order to provide at least some regulation for roro passenger ships (MEPC, 2014). The required EEDI is now defined for ro-ro passenger ships as:

Required EEDI $=(1-X / 100) \times$ Reference line value

where $X$ is the reduction factor as specified in Table 1 , and the Reference line value is defined as:

Reference line value $=a \times b^{-c}$

where for ro-ro passenger ships the parameters $a, b$ and $c$ are equal to:

$a=752.16$

$b$ is the DWT of the ship, $c=0.381$ 


$$
\begin{aligned}
E E D I= & \frac{\left(\prod_{j=1}^{M} f_{j}\right)\left(\sum_{i=1}^{n M E} P_{M E(i)} \cdot C_{F M E(i)} \cdot S F C_{M E(i)}\right)+\left(P_{A E} \cdot C_{F A E} \cdot S F C_{A E^{*}}\right)}{f_{i} \cdot f_{c} \cdot f_{l} \cdot \text { Capacity } \cdot f_{w} \cdot V_{r e f}}+ \\
& +\frac{\left(\left(\prod_{j=1}^{M} f_{j} \cdot \sum_{i=1}^{n P T I} P_{P T I(i)}-\sum_{i=1}^{n e f f} f_{\text {eff }(i)} \cdot P_{A E \text { eff }(i)}\right) C_{F A E} \cdot S F C_{A E}\right)-\left(\sum_{i=1}^{n e f f} f_{\text {eff }(i)} \cdot P_{\text {eff }(i)} \cdot C_{F M E} \cdot S F C_{M E^{* *}}\right)}{f_{i} \cdot f_{c} \cdot f_{l} \cdot \text { Capacity } \cdot f_{w} \cdot V_{r e f}}
\end{aligned}
$$

Table 1. Reduction factor in phases (MEPC, 2014)

\begin{tabular}{|l|l|l|l|l|}
\hline Size & Phase 0 & Phase 1 & Phase 2 & Phase 3 \\
\hline $\begin{array}{l}1,000 \text { DWT } \\
\text { and above }\end{array}$ & n/a & 5 & 20 & 30 \\
\hline $\begin{array}{l}250-1,000 \\
\text { DWT }\end{array}$ & n/a & $0-5$ & $0-20$ & $0-30$ \\
\hline
\end{tabular}

It can be seen from Table 1 that the required EEDI will not be applicable to ro-ro passenger ships in Phase 0, i.e. until 1 January 2015.

\section{PROBLEMS IN THE EEDI CALCULATION}

Two main questions concern the definition of the attained EEDI and of the required EEDI. First is how to define the design condition(s) for which to calculate the attained EEDI. According to second IMO GHG study (2009) overall average engine load in ships is about $75 \%$ of MCR. This proved quite useful since the selection of $75 \%$ of MCR allowed the use of the $\mathrm{NO}_{x}$ technical file. For auxiliary engines SFOC is determined similarly at $50 \%$ of their MCR from their $\mathrm{NO}_{\mathrm{x}}$ technical file. But their power in the EEDI is not determined as $50 \%$ of their $\mathrm{MCR}$, but as $5 \%$ of main engines MCR. These two values can differ significantly, especially in ro-ro passenger ships, so the use of $50 \%$ of MCR as the reference value for auxiliary engine power is proposed.

The other question concerns the comparison of different ships by the introduction of the Reference line which is currently a function of the ships capacity.

It has to be pointed out that the EEDI in this form does not observe ship as the source of the $\mathrm{CO}_{2}$ emission because it does not observe directly ship prime movers which are the $\mathrm{CO}_{2}$ producers. Instead of the $\mathrm{CO}_{2}$ producers, it observes power consumers. This is a major issue if the connection between $\mathrm{CO}_{2}$ producers and power consumers is not straightforward, like in integrated power systems. Because of that, the current EEDI formula may not be applicable for diesel-electric, turbine or hybrid propulsion systems.
Another reason why the EEDI in its current form is not applicable to more complex power systems is that the EEDI calculation is based on a generic and simplified marine power plant as shown in Figure 2 (MEPC, 2014). This scheme can only represent basic conventional power systems. For cruise passenger ships having non-conventional propulsion a more detailed scheme is provided, Figure 3. However, the labels in the scheme do not match the nomenclature in the text. Previous versions of the EEDI calculation guidelines had numerous inconsistencies (Ancic et al, 2013).

Many of them were corrected in the new 2014 guidelines, but some are still present. For example, according to Figures 2 and 3 $P_{P T I}$ can be understood either as the mechanical power that shaft motors generate, or as the electric power that they consume. And according the text in MEPC (2014) $P_{P T I}$ is actually the mechanical power that auxiliary engines generate in order to satisfy the needs of the shaft motor(s). Another issue is $P_{M E}$ which is defined as:

$$
\sum_{i=1}^{n M E} P_{M E(\mathrm{i})}=0.75 \times\left(\sum M C R_{M E(\mathrm{i})}-\sum P_{P T O(\mathrm{i})}\right)
$$

where $M C R$ is defined as "the rated installed power for each main engine" and $P_{\text {PTO }}$ as "75 per cent of the rated electrical output power of each shaft generator". These two definitions are not consistent since $M C R$ refers to the mechanical and $P_{P T O}$ to the electrical power.

Also, the EEDI formula includes innovative energy efficient technologies in members $P_{\text {eff }}$ and $P_{\text {AEeff, but does not give clear }}$ guidelines on how to assess the influence of these technologies on the ship energy efficiency. Because of that, the Guidance on treatment of innovative energy efficient technologies (MEPC, 2013) has been adopted and circulated. However, the complexity of the $P_{\text {eff }}$ and $P_{\text {AEeff }}$ calculation clouds the physical meaning of the EEDI even more. 


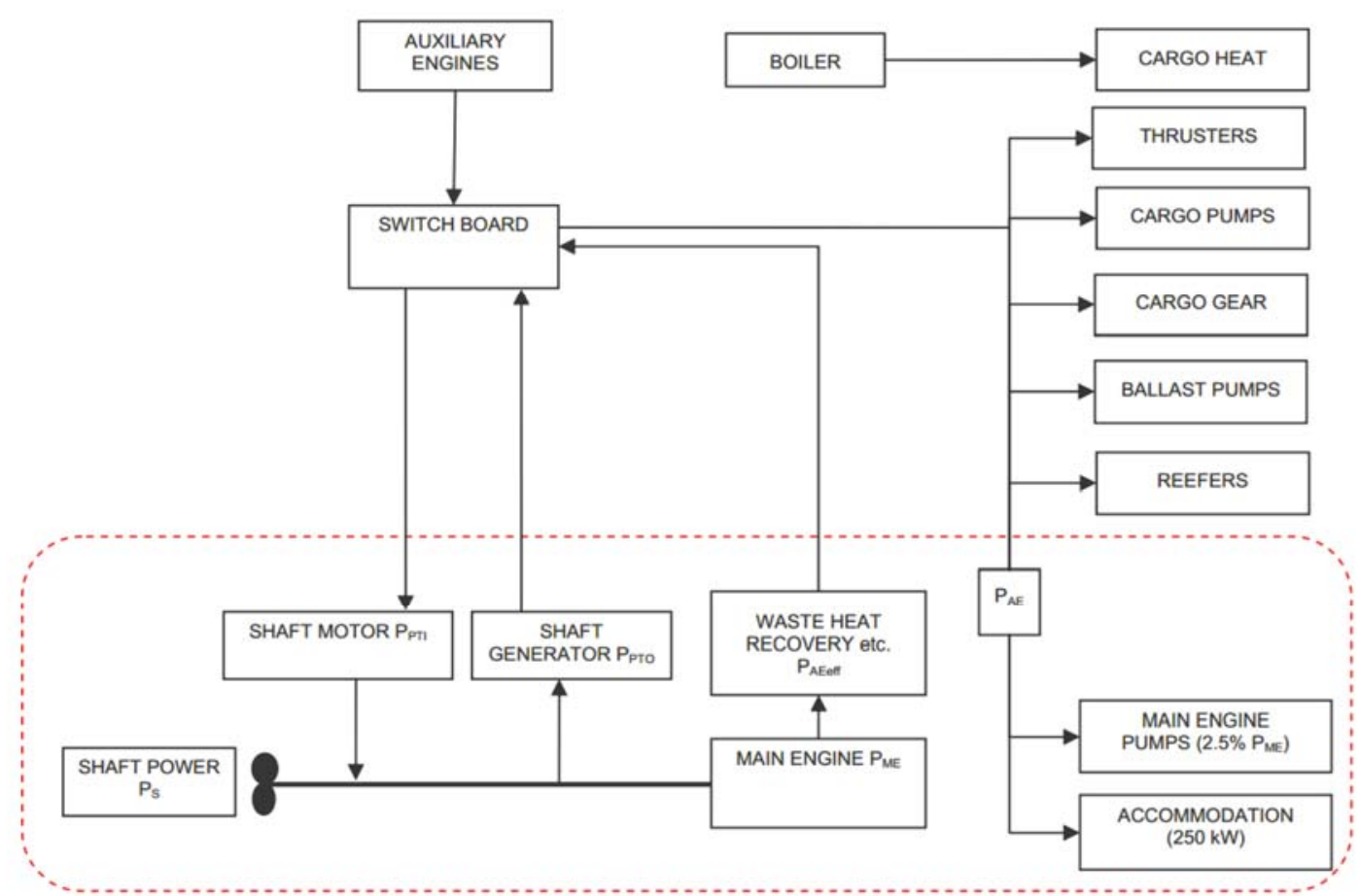

Figure 2. A generic and simplified marine power plant (MEPC, 2014)

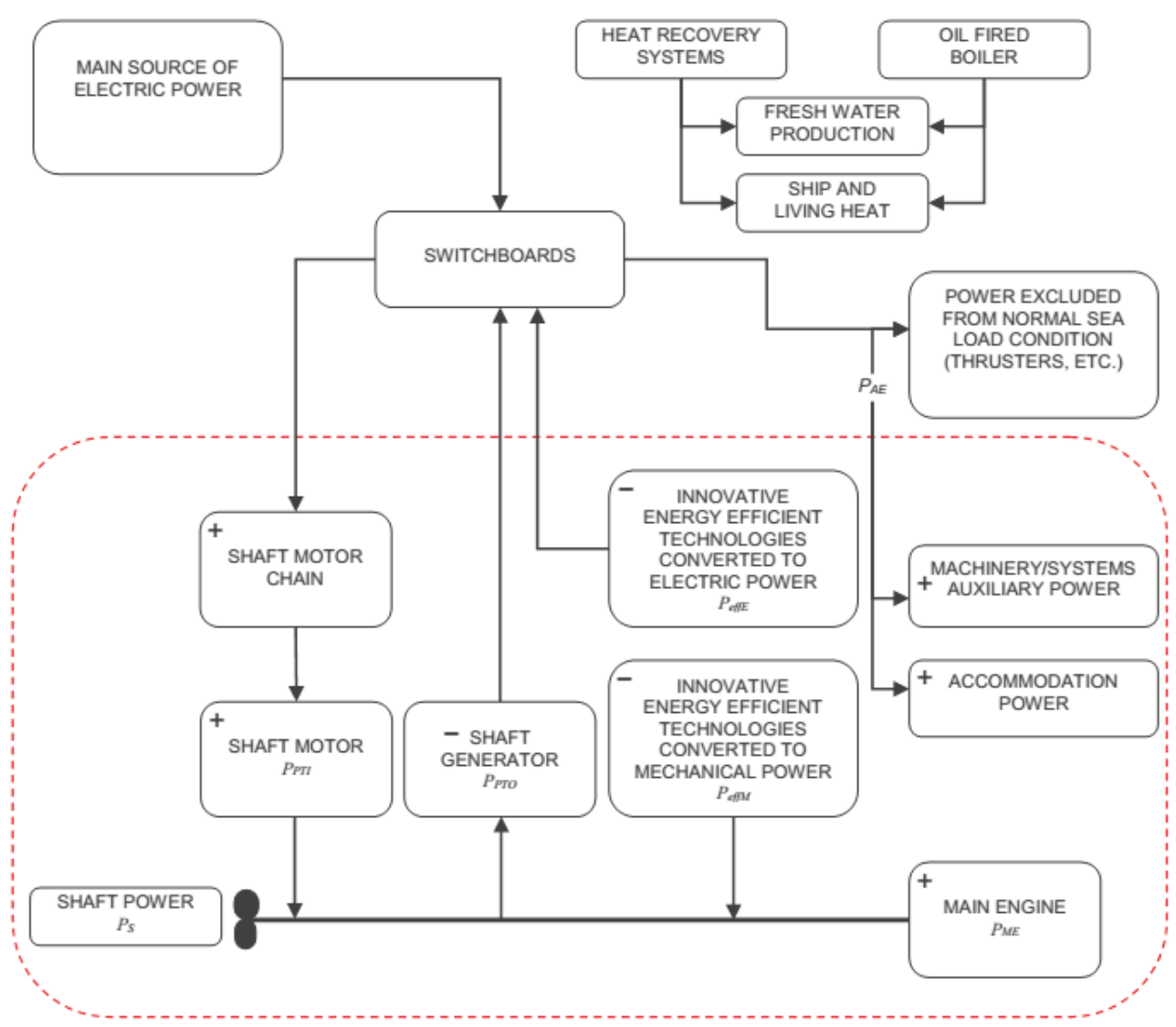

Figure 3. A generic and simplified marine power plant for a cruise passenger ship having non-conventional propulsion (MEPC, 2014) 
It is necessary to emphasize that, even though closely related, the increase in the energy efficiency and the reduction in the $\mathrm{CO}_{2}$ emission are not synonyms. The difference can be most clearly observed in technologies that do not use carbon based fuels, like nuclear, hydrogen and solar power systems. Due to safety and other limitations, their energy efficiency is much lower, but they have zero $\mathrm{CO}_{2}$ emission.

The term energy efficiency is the ratio of energy output and energy input. When observing engines, the specific fuel oil consumption $S F O C$ is the best indicator of its energy efficiency. When looking back to the EEDI development, it can be seen that it originated from the $\mathrm{CO}_{2}$ Index. This index also had a clear physical meaning: it represented relative $\mathrm{CO}_{2}$ emission, i.e. the amount of the $\mathrm{CO}_{2}$ emitted in grams per tonnes of cargo transported over the distance in miles. The main difference compared to the current EEDI formula is that the numerator in the $\mathrm{CO}_{2}$ Index represented the total ships $\mathrm{CO}_{2}$ emission. It included not only main and auxiliary engines, but also boilers, incinerators etc. Another difference is that the current EEDI formula is drastically expanded with the introduction of numerous correction factors in order to satisfy the statistical correlations. Because of that the current EEDI ceased to be the measure of the relative $\mathrm{CO}_{2}$ emission, but has not become the measure of energy efficiency either.

It can be also observed that one of the easiest and most effective ways to improve EEDI in its current form is to lower the design speed. This leads to the conclusion that ships with reduced speed have much higher energy efficiency, when in fact the efficiency of their propulsion system might be significantly lower.

Also a major problem was the determination of the required EEDI. In the current approach numerous correction factors are being used to determine the attained EEDI. But the process of determining the required EEDI does not include these factors because the data required for that are not included in HIS Fairplay Database. An extensive study has been undertaken in order to determine the required EEDI for passenger, ro-ro passengers and ro-ro ships (Deltamarine, 2011). It concluded that in its present form, the EEDI is not feasible for regulating the energy efficiency of ro-ro cargo, ro-ro passenger and passenger ships because the design criteria for these ship types vary too much. Thus, a new approach is required.

\section{RECOMMENDED METHODOLOGY}

The study performed by Deltamarine (2011) concluded also that the inclusion of the speed in the Reference line calculation for ro-ro passenger ships would lead to the satisfactory statistical correlation. This was done by dividing ships into different speed groups and then calculating the Reference line for each group.

Even better correlation could be achieved if the Reference line would be substituted by the Reference surface. In the current approach the Reference line value is determined as a function of the ships capacity according to (7). In the recommended approach the Reference surface value would be a function of the ships capacity and speed determined by:

Reference surface value $=a \times b^{-c} \times d^{e}$

where $b$ would be the capacity for ro-ro passenger ships (preferably in GT), $d$ would be the speed, and $a, c$ and $e$ would be statistically defined parameters. The value of $c$ would probably be a bit higher than in the current approach because the parameter $e$ would account for different design speeds.

With the introduction of the speed as the parameter in the calculation of the Reference surface value a modification of the attained EEDI calculation would also be possible. Instead of observing only one operating point (which in some cases might never be encountered in ships operation), a combination of different loads might be introduced. This approach would be similar as for the $\mathrm{NO}_{\mathrm{X}}$ regulation (MEPC, 2008). The $\mathrm{NO}_{\mathrm{X}}$ technical code defines test cycles for different engine application and weighting factors for each load. It requires that the total weighting $\mathrm{NO}_{\mathrm{X}}$ emission is not higher than required by MARPOL as well as that the specific emission at each individual mode point is not higher by more than $50 \%$ of the allowable emission. The same approach could be implemented for the EEDI as well. That would make the comparison of ships with the same capacity but different design speeds possible.

Also, the $\mathrm{NO}_{\mathrm{X}}$ technical code contains data from direct measurements of the $\mathrm{CO}_{2}$ emission for different engine loads. The use of this data directly would simplify the calculation of the attained EEDI. Also it has to be emphasized that the introduction of any innovative technologies can be observed either through reduced $\mathrm{CO}_{2}$ emission from prime movers or through increased transport work. In either case the influence of these technologies is already visible in the attained EEDI value, so they should not be considered additionally.

Figure 4 gives a qualitative representation of how the Reference surface would look like as a function of the capacity and the speed. The points describe the average EEDI for different engine loads (resulting in different reference speeds) and different ship capacity. Figure 5 shows how the two ships of the same capacity can have different EEDI values. In the current approach ship A would be considered better since only $75 \%$ MCR is taken into account. In the suggested approach ship B would be considered better. It can be clearly seen from Figure 5 that the ship $B$ has significantly lower EEDI when the comparison is made for the same speed. 


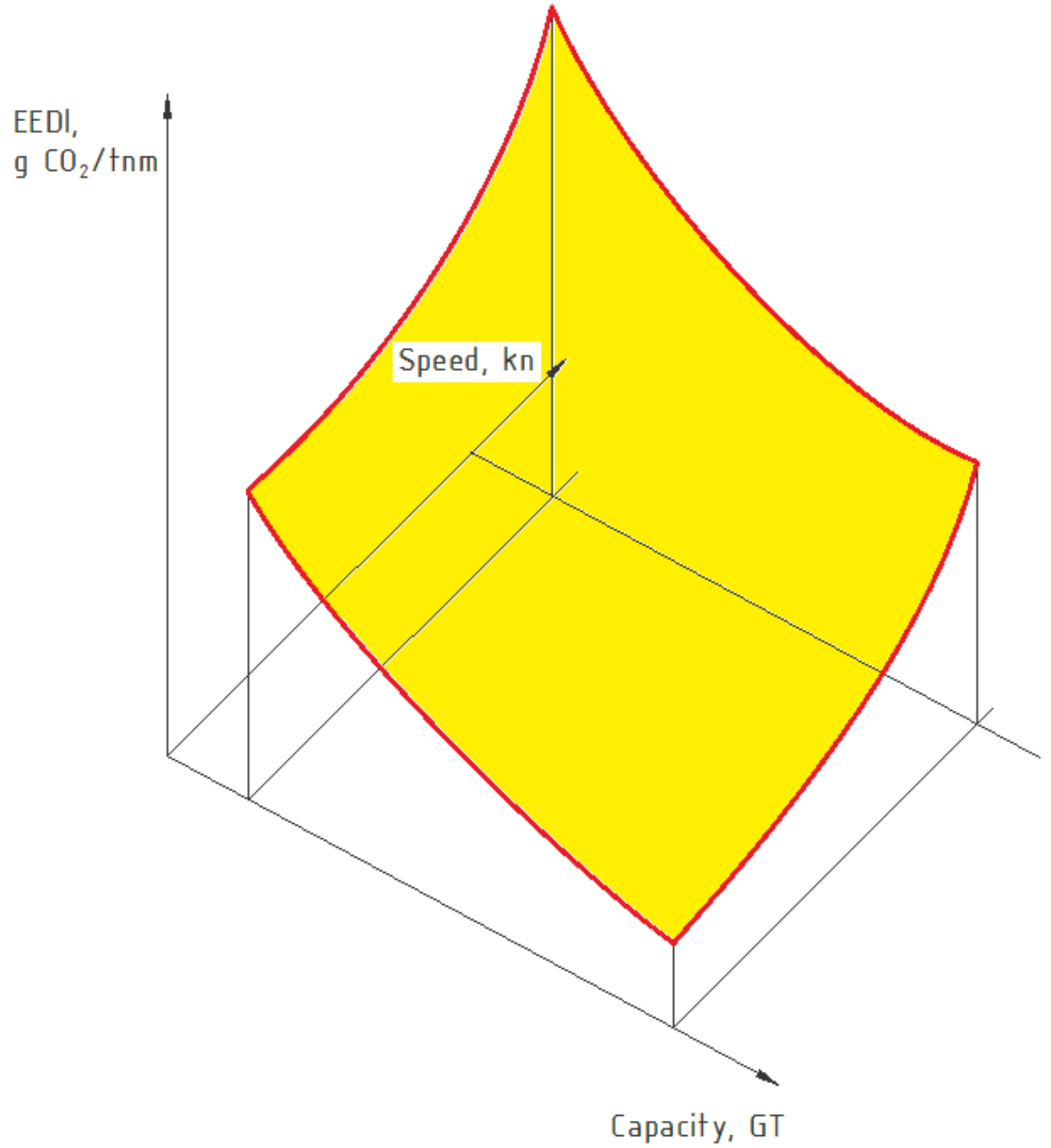

Figure 4. A qualitative representation of the Reference surface: EEDI as a function of capacity and speed 


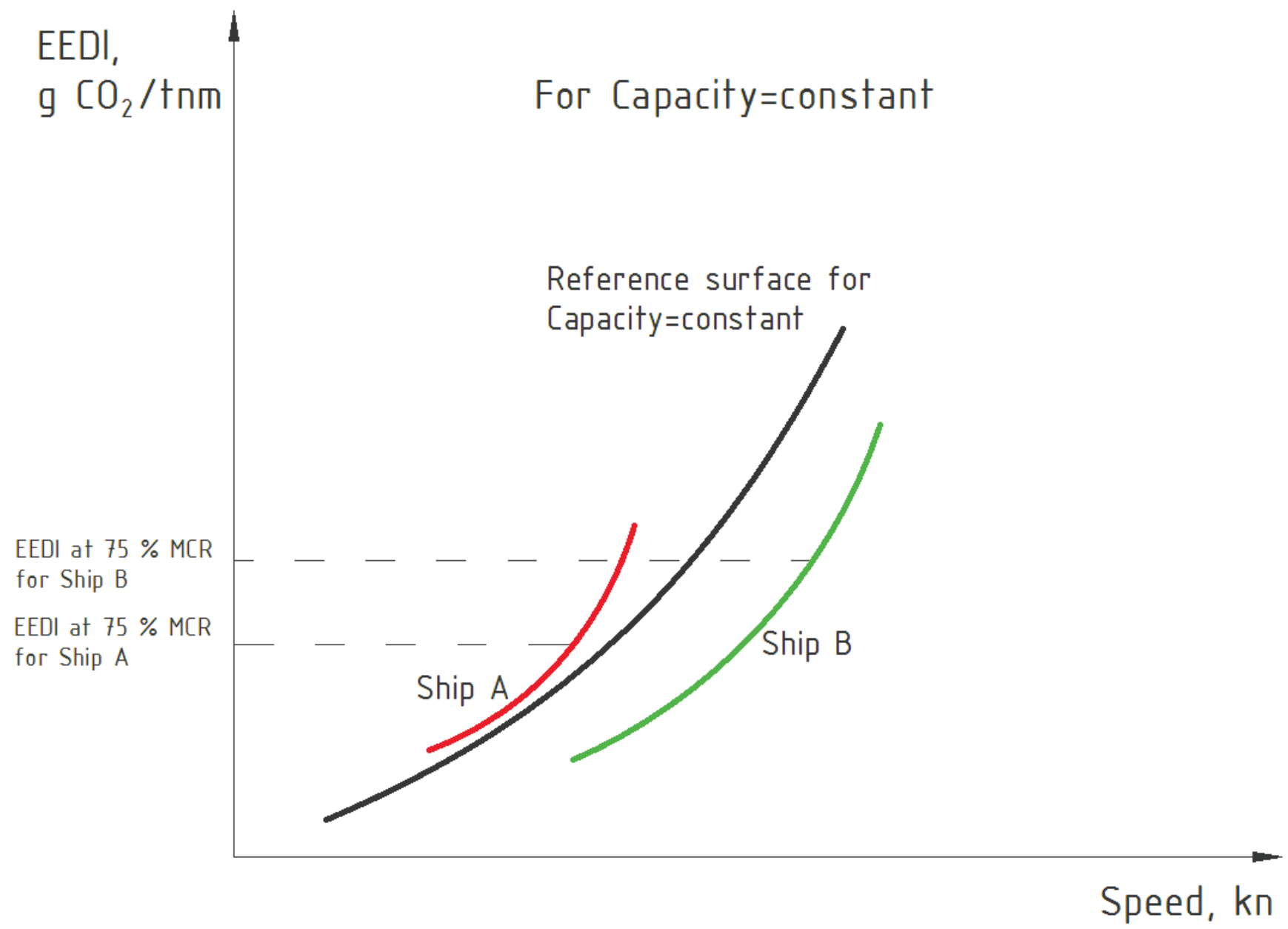

Figure 5. An example of the attained EEDI for two ships with the same capacity and different design speeds

\section{CONCLUSION}

The environmental impact of ships has to be regulated and the initiative to reduce $\mathrm{GHG}$, i.e. $\mathrm{CO}_{2}$ emission, is praiseworthy. EEDI, as a technical measure, has a great potential for GHG emission reduction. In its current form EEDI is applicable to majority of ships. But the current approach in the attained EEDI calculation is very rigid and unable to be adapted to the new configurations of ship's power systems. This is a major flaw since the EEDI is intended to encourage innovations in ship power systems. Also the current approach that defines the required EEDI as a function of the capacity proved deficient for ships which design criteria vary too much.

This paper proposes a new approach to the EEDI definition for ro-ro passenger ships. It introduces the Reference surface as the function of ships capacity and speed instead of the Reference line. It also expands the attained EEDI calculation to different loads trying to give a clearer view of the ships $\mathrm{CO}_{2}$ emission, similarly as for the $\mathrm{NO}_{\mathrm{X}}$ regulation. In that case the numerous correction factors cease to be required and the EEDI retains its physical meaning as a relative $\mathrm{CO}_{2}$ emission. This modified
EEDI allows a fair comparison between different ro-ro passenger ships. This approach is applicable also for other ship types. However, since the current methodology adopted by MEPC showed satisfactory results for other ship types, this approach is not required.

The future work will include a detailed study on the applicability of this new approach for ro-ro passenger ships. This study will be based on the data from IHS Fairplay database and performed within the same research project.

\section{ACKNOWLEDGMENT}

This research is supported by the European Social Fund and the Croatian Ministry of Science, Education and Sport within the operational Programme Human Resources Development (Grant No. HR.3.2.01 -0030).

\section{REFERENCES}

Ančić, I., Šestan, A. Influence of the required EEDI reduction factor on the $\mathrm{CO}_{2}$ emission from bulk carriers, Energy Policy 84(2015) 107-116, 2015. 
Ančić, I., Šestan, A. Vladimir, N. EEDI calculation for passenger and ro-ro passenger ships, Proceedings of the Design \& Operation of Passenger Ships Conference. RINA, London, UK, 2013.

Deltamarine Study on Tests and Trials of the Energy Efficiency Design Index as Developed by the IMO, Report for Project 6543, Raisio, Finland, 2011.

MEPC Report of the Marine Environment Protection Committee on its Sixty-Second Session, MEPC 62/24, London, UK, 2011a.

MEPC $\mathrm{NO}_{X}$ Technical Code, MEPC Resolution 177(58), London, UK, 2008.

MEPC Marginal Abatement Costs and Cost Effectiveness of Energy-Efficiency Measures, MEPC 62/INF.7, London, UK, $2011 \mathrm{~b}$.

MEPC Report of the Marine Environment Protection Committee on its Sixty-Third Session, MEPC 63/23, London, UK, 2012.

MEPC 2013 Guidance on Treatment of Innovative Energy Efficient Technologies for Calculation and Verification of the Attained EEDI, MEPC.1/Circ.815, London, UK, 2013.

MEPC 2014 Guidelines on the Method of Calculation of the Attained Energy Efficiency Design Index (EEDI) for New Ships, MEPC Resolution 245(66), London, UK, 2014.

Runko Luttenberger, L., Ančić, I., Šestan, A. The viability of short-sea shipping in Croatia. Brodogradnja 64 (4), 472-481, 2013.

Second IMO GHG study 2009. International Maritime Organization (IMO) London, UK, 2009

Third IMO GHG Study 2014. International Maritime Organization (IMO) London, UK, 2014 